\title{
The Adoption of Climate Smart Agriculture: The Role of Information and Insurance Under Climate Change
}

\author{
Jamie Mullins, Joshua Graff Zivin, Andrea Cattaneo, \\ Adriana Paolantonio, and Romina Cavatassi
}

\begin{abstract}
Climate change adds to the existing challenges in improving crop productivity and welfare for smallholder agricultural households by affecting the mean and variability of weather conditions and the frequency of extreme weather events. In the face of such growing uncertainty, agricultural practices of small landholders need to be adapted to better manage the changing risk structures. Since government risk management programs may complement or substitute for farmer adaptation, this chapter examines how a range of institutional interventions might assist, obstruct, channel, or change smallholder agricultural adaptation to climate change. Taken together, our results underscore the importance of the informational role of the agriculture extension, suggest that insurance can lead to significant changes in farmer planting and land management decisions, and show how information about changing conditions and insurance can be complimentary in driving changes in farmer behavior.
\end{abstract}

\section{Introduction}

Climate change adds to the existing challenges in improving crop productivity and welfare for smallholder agricultural households by affecting the mean and variability of weather conditions and the frequency of extreme weather events. In the face of such growing uncertainty, agricultural practices of small landholders need to be

\author{
J. Mullins ( $\square)$ \\ Department of Resource Economics, University of Massachusetts Amherst, \\ Amherst, MA, USA \\ e-mail: jmullins@umass.edu \\ J.G. Zivin \\ School of Global Policy and Strategy, University of California San Diego, San Diego, CA, USA
}

A. Cattaneo

FAO of the UN, Rome, Italy

A. Paolantonio $\bullet$ R. Cavatassi

International Fund for Agriculture Development (IFAD), Rome, Italy 
adapted to better manage the changing risk structures. Since government risk management programs may complement or substitute for farmer adaptation (Anton et al. 2013), this chapter examines how a range of institutional interventions might assist, obstruct, channel, or change smallholder agricultural adaptation to climate change.

Our analysis begins with a stylized conceptual model from which we build a series of simulations based on empirical data from smallholder agriculture households in Malawi. We proceed by analysing three climate change scenarios, looking at the spectrum of farmer responses as a function of extension information provision, weather index insurance, and the interaction of the two institutions.

Our approach grapples with three distinct dimensions of uncertainty central to understanding how the policies of an institutional actor might affect smallholder agricultural adaptation to climate change. First, uncertainty about farmers' perceived risks and their degree and direction of adaptation response to climate change is addressed through the implementation of an empirically founded expected-utilityoptimization framework which accounts for farmer risk preferences and the role of weather conditions and yield variability in adaptation decisions. Second, we address uncertainty about the quantitative impacts of climate change on the variability of yields and production risks through a regression analysis linking weather conditions and yields across a range of crops and conservation techniques. Finally the wide range of possible policy options is narrowed through a focus on the effects of two program types: information provision regarding likely changes in weather conditions under climate change and weather indexed insurance coverage.

The basis of the analysis in this chapter is that climate change affects the distribution of weather conditions during the growing season, which in turn impacts yields under a given set of management practices. ${ }^{1}$ Changes in yield distributions ultimately alter expected farmer incomes, and thus planting and management decisions. In our simulations, farmers can adopt adaptation strategies along two distinct dimensions. First, farmers can change cropping decisions between staple and cash crops and amongst crop types within these categories. Second, farmers can make changes in land management practices through the adoption of Climate Smart Agricultural (CSA) techniques (e.g. Kassie et al. 2008; Rosenzweig and Binswanger 1993; Heltberg and Tarp 2002; Deressa and Hassan 2010). CSA practices that are considered in the simulations include intercropping of staple (maize) and cash (legumes) crops, as well as the improvement of soil water-holding capacity by adding crop residues or manure, and/or by adopting conservation tillage in response to changes in water availability (Smith and Olesen 2010). Investments in soil-water holding capacity (SWC) may be a particularly important adaptive response in light of recent research that finds a positive correlation between rainfall variability and the selection of SWC type practices (Arslan et al. 2013).

\footnotetext{
${ }^{1}$ A necessary limitation of our simulations is that they rely upon data from the 2009-2010 growing season and thus cannot attend to new seed varieties or cultivation practices that may arise in the face of climate change.
} 
This chapter focuses on how smallholder adaptation to changing conditions under climate change might be affected by government risk management interventions. While Mendelsohn (2010) finds that farmers without insurance have a strong incentive to adapt to climate change, Skees et al. (1999) show that the assumption of risk by farmers may stymie farmer investment in certain adaptation strategies. Collier et al. (2009) underscore the importance of specific policy design features in impacting behaviour. For example, traditional agricultural insurance (which makes an indemnity payment when the farm incurs a verifiable production loss) can help to manage production risk but may diminish incentives to adapt to climate change. Conversely, area-yield insurance and weather index insurance (as we examine in this chapter) approaches can minimize these moral hazard concerns since indemnities are paid independently of the actual loss incurred by a policyholder. Of course, all risk management policies will change the framework under which farmers make production decisions. Deepening our understanding of how institutional policies impact farmer decisions under climate change is of critical importance for welldesigned climate adaptation strategies now and in the future.

The following questions anchor our analyses as we build on previous work examining risk management under climate change (Collier et al. 2009; Heltberg et al. 2009, Anton et al. 2013).

1. Can policy makers assist in risk management without steering farmers away from beneficial adaptation?

2. How do insurance and information programs impact farmer behaviours and might these two policy approaches interact in their effects on farmer decisions?

3. How can policy makers decide between interventions when the information about how various instruments would perform under an increasingly variable climate is very limited?

The contribution of this chapter is to address - in the context of smallholder agriculture in Malawi - the risk and the uncertainties introduced by climate change and the role of perceptions regarding this uncertainty in shaping farmer decisions and the appropriate risk management instruments to improve smallholder welfare.

\section{Conceptual Model}

In this section, we develop a basic model of smallholder agricultural management when yields are stochastic and farmers are risk averse. We begin with the assumption that farmers are growing a single staple crop on a fixed plot of land. Farmers maximize their expected utility from profits by choosing agricultural inputs, $x$, and techniques, $\phi$. The vector $\mathbf{x}$ will include a range of purchased agricultural inputs, such as fertilizer, pesticides, herbicides, and seed. The variable $\phi$ will correspond to the labour requirements of the dominant agricultural technique used to cultivate the crop. In this model, possible techniques include a variety of CSA practices as well as more chemically-intensive ones. The key distinction between inputs and 
technique is that the former is assumed to impact expected yield while the latter is assumed to impact the volatility of yield. ${ }^{2}$ Without loss of generality, we define $\phi$ as the intensivity with which the chosen technique reduces yield volatility.

In particular, agricultural yield on land of given quality is equal to $f(x)+2(1-g(\phi))$ $\theta$, where $\theta$ is a stochastic weather variable with an expected value of zero and variance $\sigma^{2}$ (Just and Pope 1978). ${ }^{3}$ Expected yield $\mathrm{f}$ is assumed to be increasing in inputs at a decreasing rate, i.e. $\mathrm{f}^{\prime}(\mathrm{x})>0, \mathrm{f}^{\prime}(\mathrm{x})<0$. The function $\mathrm{g}$ can be thought of as a measure of protection against weather volatility, such that 1-g is a measure of weather sensitivity (Graff-Zivin and Lipper 2008). Protection is assumed to be increasing in technique at a decreasing rate, i.e. $\mathrm{g}^{\prime}(\phi)>0, \mathrm{~g}^{\prime}(\phi)<0$. Let $\mathrm{p}$ represent the market price per unit of agricultural output. For simplicity, we will also assume that this price represents the per unit value of agricultural output consumed by the farmer, which is tantamount to assuming that all farmers have market access and that food production levels always exceed the subsistence demands of the household.

Revenue can thus be expressed as $R=p f(x)-2 p(1-g(\phi)) \sigma^{2}$. Taking a secondorder Taylor-Series approximation of EU(R) yields the following expression:

$$
E U(R) \approx p f(x)-r p(1-g(\phi)) \sigma^{2},
$$

where $r$ is the Arrow-Pratt measure of risk aversion. Utility from agricultural revenues is increasing in average yield and decreasing in the variability of yields. This type of utility function is frequently used in finance (Markowitz 1987) and can be viewed as a special case of the more general class of mean-variance utility functions. The properties of these utility functions and their consistency with expected utility theory are discussed in great detail elsewhere (Meyer 1987).

Turning to costs, several differences between inputs and technique are worth highlighting. First, inputs require market purchases early in the growing season that only pay dividends at harvest. As such, limited savings and the imperfect credit markets that are commonplace in developing countries may play an important role in input purchases. On the other hand, technique will generally be 'purchased' with household labor. Since technique does not require an initial cash outlay, credit constraints should be immaterial. In particular, we let $\lambda$ represent the costs of credit, which can be viewed as the shadow value on a credit constraint. A larger $\lambda$ represents dearer credit and thus raises the effective costs of input purchases while leaving the costs of technique unaffected.

Second, the nature of costs for the $x$ and $\phi$ choice variables also differ, independent of cash flow concerns. While the costs of inputs are based on market prices net of any subsidies, the costs of technique are a bit more complicated. This complication arises because we would like to allow for the possibility that technique can be

\footnotetext{
${ }^{2}$ As will be made clear below, technique can potentially impact long-term expected yields. Since these benefits will accrue with a considerable delay, they are best reflected in an appropriately discounted cost function.

${ }^{3}$ The assumption of additive risk can be relaxed during simulations.
} 
mean yield augmenting in the long-run. For example, several studies suggest that conservation agriculture can increase expected yield after a 3-5 year period of ecosystem disequilibrium (see Graff, Zivin and Lipper 2008). Rather than model this as part of $\mathrm{f}()$, which would require more explicit assumptions regarding the timing of those benefits, we include them in the 'effective' costs of technique. In particular, we assume that the costs of technique will include the direct costs of its application net of the present discounted value of any future yield benefits. As such, the per-unit costs of technique will be a function of discount rates $\delta$.

We denote the costs of inputs as $c_{x}$ and the costs of technique as $c_{\varphi}(\delta)$, with the usual assumption regarding the convexity of costs, such that the cost of technique are increasing in discount rates at an increasing rate, e.g. $\mathrm{c}_{\varphi}{ }^{\prime}>0$ and $\mathrm{c}_{\varphi}{ }^{\prime}>0$. Moreover, we introduce the terms $\left(1-s_{x}\right)$ and $\left(1-s_{\varphi}\right)$ to denote targeted government subsidies for inputs and technique, respectively. Suppressing the expected utility notation, the objective of the farmer is to maximize the expected utility of profits, which can be expressed as follows:

$$
\pi=p f(x)-p(1-g(\phi)) r \sigma^{2}-\left(1-s_{x}\right) \lambda c_{x} x-\left(1-s_{\phi}\right) c_{\phi}(\delta) \phi
$$

The first order conditions imply:

$$
\begin{gathered}
p \frac{\partial f}{\partial x}-\left(1-s_{x}\right) \lambda c_{x}=0 \\
p \frac{\partial g}{\partial \phi} r \sigma^{2}-\left(1-s_{\phi}\right) c_{\phi}(\delta)=0 .
\end{gathered}
$$

Inputs and technique will be chosen such that the marginal benefits from each will be equal to its marginal cost, net of subsidies. In the case of inputs, these costs will also depend on borrowing costs as measured by $\lambda$. The marginal benefits from inputs are due to expected yield augmentation. The marginal benefits from technique are due to protection from yield volatility.

\subsection{Inputs, Technique, Insurance, and Diversification}

This basic framework can be generalized to expand the portfolio of farmer investment options by introducing the possibility of insurance coverage, $\psi$, and crop diversification, D. Insurance could play an important role in this setting going forward, as climate change is expected to increase yield volatility considerably. Since credible documentation of individual farmer yield losses is likely prohibitively expensive and/or infeasible in the developing country context, we assume that insurance contracts are written based on 'local' realizations of weather. Of course, yield volatility depends on weather, among other things, so one can view this insurance 
contract as one that partially indemnifies households against agricultural risk. Moreover, since it is based on weather rather than experienced yields that will also depend on a host of farmer behaviors, it eliminates very practical concerns about moral hazard.

In particular, we view insurance as a state-contingent contract, where farmers receive a payment $\mathrm{Z}$ that depends on the probability of a given weather realization and thus the variance of weather, and the amount of insurance coverage purchased. This insurance is distinct from the type of 'insurance' purchased through the use of technique since insurance shrinks downside risk while technique decreases both downside and upside risk by compressing volatility. More formally, $Z\left(\psi, \sigma^{2}\right)$, where the payout $\mathrm{Z}$ is increasing in coverage and volatility at a decreasing rate. Similar to agricultural inputs, this contract is purchased at the beginning of the growing season in return for protection in the future, so the costs of credit will play a role in the purchase decision. Insurance costs are increasing and convex with the volatility of weather, reflecting the additional costs of provision by insurers.

It is interesting to note that while the value of insurance (or for that matter technique) to farmers depends on perceived volatility, the premiums are expected to depend on actual volatility as understood by insurers. ${ }^{4}$ To formalize the notion of this wedge between perceptions and actual, we introduce the term $m$ such that the true volatility $\sigma_{T}^{2}=\sigma^{2} / m^{2}$, with $0<m<1$. When $m=0$ farmers believe weather to be non-stochastic. When $m=1$ they have a perfect estimate of volatility. All cases in between correspond to the case where farmers underestimate the realization of weather by a fixed proportion equal to $m$. As with inputs and technique, we allow the government to subsidize the purchase of insurance, such that the 'effective' cost of purchase can be expressed as: $\left(1-s_{\psi}\right) \lambda c_{\psi}\left(\sigma^{2} / m^{2}\right){ }^{5}$

Our approach to modelling diversification is highly stylized to maintain a focus on the core tradeoffs associated with pursuing this strategy rather than the specifics of alternative crops. In particular, we assume that diversification helps protect farmers against revenue volatility in much the same way as technique, i.e. we assume $g$ is increasing in diversification at a decreasing rate. The costs of diversification depend on the net expected revenue reductions associated with planting it instead of the staple crop; simply denoted by $c_{D}$. Since these costs are only realized at harvest time, credit is not a concern for this strategy. Allowing subsidies for diversification strategies, denoted $\mathrm{s}_{\mathrm{D}}$, we can rewrite the farmers expected profit function as follows:

$$
\pi=p f(x)-p(1-g(\phi, D)) r \sigma^{2}+Z\left(\psi, \sigma^{2}\right)-\lambda\left(1-s_{x}\right) c_{x} x
$$

\footnotetext{
${ }^{4}$ One notable exception is the case where insurance markets are not competitive, since insurers will be able to set prices, at least partly, based on farmer perceptions as embodied in their willingness to pay for insurance.

${ }^{5}$ We also note that government safety nets can be viewed as a special case of insurance that is offered at fixed coverage levels with zero direct cost to the farmer.
} 


$$
-\left(1-s_{\phi}\right) c_{\phi}(\delta) \phi-\lambda\left(1-s_{\psi}\right) c_{\psi}\left(\sigma^{2} / m^{2}\right) \psi-\left(1-s_{D}\right) c_{D} D
$$

This yields the following FOCS:

$$
\begin{gathered}
p \frac{\partial f}{\partial x}-\lambda\left(1-s_{x}\right) c_{x}=0 \\
p \frac{\partial g}{\partial \phi} r \sigma^{2}-\left(1-s_{\phi}\right) c_{\phi}(\delta)=0 \\
\frac{\partial Z}{\partial \psi}-\lambda\left(1-s_{\psi}\right) c_{\psi}\left(\sigma^{2} / m^{2}\right)=0 \\
p \frac{\partial g}{\partial D} r \sigma^{2}-\left(1-s_{D}\right) c_{D}=0
\end{gathered}
$$

Here again we see that investments are made such that the marginal benefit of those investments is equal to the marginal costs of those investments. Since the role played by agricultural inputs is independent of the other investment activities - it only affects expected yield - optimal input usage is identical to that found in our simpler case. The introduction of diversification, which competes with technique to shape effective risk exposure, makes the role of policy levers more complicated. Since insurance contracts are written on weather rather than agricultural yield, optimal coverage is orthogonal to the other risk management strategies. Although our simulations do not address credit constraints, it is worth noting that input usage and insurance purchases will depend upon the state of credit markets, while technique and diversification eschew such concerns. ${ }^{6}$

\subsection{The Impacts of Climate Changes: Weather Volatility and Extension}

As noted earlier, uncertainty about weather and attendant yield volatility are expected to increase under climate change. While volatility has no impact on input usage, its impacts on technique and diversification are straightforward. Greater volatility leads to greater perceived volatility (except in the special case where $\mathrm{m}=0$ ) and thus increases the returns to protection from yield risk. How much additional investment is made in each will depend on the curvature of the risk protection function $\mathrm{g}$ in technique and diversification spaces.

\footnotetext{
${ }^{6}$ If investments can be differentially collateralized or credit is targeted toward particular actions, credit constraints can differ for each type of expenditure.
} 
In contrast, the impact of uncertainty on the purchase of insurance is ambiguous. The net effect will depend on the relative curvatures of the payout and cost function. It will also depend on the wedge between actual and perceived uncertainty since expected benefits are based on farmer perceptions but the price of insurance will be driven by the true underlying risk. The more farmers underestimate the risk (as $\mathrm{m}$ approaches zero) the larger the first term in brackets and the more likely insurance will be decreasing in risk. Put another way, the more farmers misjudge risk the more they will undervalue insurance relative to its costs and the less likely they are to purchase it.

$$
\begin{gathered}
\frac{d x}{d \sigma^{2}}=0 \\
\frac{d \phi}{d \sigma^{2}}=p \frac{\partial^{2} f}{\partial x^{2}} \cdot \frac{\partial^{2} z}{\partial \psi^{2}}\left[\left(p \frac{\partial g}{\partial \phi} r\right)\left(p \frac{\partial^{2} g}{\partial D^{2}} r \sigma^{2}\right)-\left(p \frac{\partial^{2} g}{\partial \phi \partial D} r \sigma^{2}\right)\left(p \frac{\partial g}{\partial D} r\right)\right] /|H|>0 \\
\frac{d \psi}{d \sigma^{2}}=\left[\left(1-s_{\psi}\right) \lambda \frac{\partial c_{\psi}}{\partial \sigma^{2}} \frac{1}{m^{2}}-\frac{\partial^{2} z}{\partial \psi \partial \sigma^{2}}\right] / \frac{\partial^{2} z}{\partial \psi^{2}} \frac{<}{>} 0 \\
\frac{d D}{d \sigma^{2}}=p \frac{\partial^{2} f}{\partial x^{2}} \cdot \frac{\partial^{2} z}{\partial \psi^{2}}\left[\left(p \frac{\partial g}{\partial D} r\right)\left(p \frac{\partial^{2} g}{\partial \phi^{2}} r \sigma^{2}\right)-\left(p \frac{\partial^{2} g}{\partial \phi \partial D} r \sigma^{2}\right)\left(p \frac{\partial g}{\partial \phi} r\right)\right] /|H|>0
\end{gathered}
$$

While we have not yet formally modeled policies to expand agricultural extension, nearly all of the comparative statics described above could be influenced by it. If, for example, an increase in extension efforts helps farmers understand that appropriate fertilizer applications can increase their yields, then this is tantamount to a change in the function $f$ to the farmer. Similarly, if extension provides farmers with new information about diversification opportunities or new agricultural techniques, this translates into a change in the function $g$ from the farmer's perspective. Since $f$ and $g$ feature prominently in all expressions above, extension of this sort will influence optimal decision making as well as the responsiveness of optimal decision making to changes in other policies and parameters. ${ }^{7}$

One such parameter that deserves particular attention is misperceptions regarding weather volatility. In particular, it is possible that extension could make targeted efforts to help farmers better understand weather and help them update their heuristics under a changing climate. This is, in fact, one of the risk management interventions we will examine via simulation in later sections.

\footnotetext{
${ }^{7}$ The impacts of extension could also be linearly approximated by modeling them as changes in the 'effective' costs of inputs, technique, insurance, and diversification. In this case, the impacts of extension will be entirely analogous to the earlier analysis on subsidies. Whether such an approximation is a reasonable one remains an empirical question.
} 
Formally, we can view extension efforts to increase farmer understanding of weather conditions as an effort to increase the parameter $m$. In this case, it is straightforward to show that all of the risk reducing activities - technique, diversification, and insurance - are increasing in $m$ and thus increasing in extension (or other informational) activities that move farmer priors closer to 'actual' distributions under a changing a climate. Letting $\sigma_{T}^{2}$ denote true weather volatility (as opposed to perceived volatility) the specific relationships are as follows:

$$
\begin{gathered}
\frac{d x}{d m}=0 \\
\frac{d \phi}{d m}=p \frac{\partial^{2} f}{\partial x^{2}} \cdot \frac{\partial^{2} z}{\partial \psi^{2}}\left[\left(2 p \frac{\partial g}{\partial \phi} r m \sigma_{T}^{2}\right)\left(p \frac{\partial^{2} g}{\partial D^{2}} r \sigma_{T}^{2}\right)\right. \\
\left.-\left(p \frac{\partial^{2} g}{\partial \phi \partial D} r \sigma_{T}^{2}\right)\left(2 p \frac{\partial g}{\partial D} r m \sigma_{T}^{2}\right)\right] /|H|>0 \\
\frac{d D}{d m}=p \frac{\partial^{2} f}{\partial x^{2}} \cdot \frac{\partial^{2} z}{\partial \psi^{2}}\left[\left(2 p \frac{\partial g}{\partial D} r m \sigma_{T}^{2}\right)\left(p \frac{\partial^{2} g}{\partial \phi^{2}} r \sigma_{T}^{2}\right)\right. \\
\left.-\left(p \frac{\partial^{2} g}{\partial \phi \partial D} r \sigma_{T}^{2}\right)\left(2 p \frac{\partial g}{\partial \phi} r m \sigma_{T}^{2}\right)\right] /|H|>0
\end{gathered}
$$

The impacts of these policy instruments on farmer welfare can be obtained by plugging the relevant relationships back into the expected profit function, defined in (5). Heterogeneity with respect to time or risk preferences can be similarly explored.

Of particular note are the predictions of Eqs. 15 and 17, which suggest that better information regarding higher weather volatility ought to lead to increased use of CSA techniques and diversification crops. These are outcomes that will be examined directly as part of the simulations in the following sections.

\section{The Simulation Framework}

While the conceptual model highlights a number of policy tools that can be used to influence farmer choices under climate change, we will limit our empirical attention to those policies that are most directly tied to the increased weather volatility that is expected under climate change. In particular, we simulate the impacts of insurance and extension policies on cropping patterns and farmer welfare under zero, modest, and more severe climate change scenarios. Simulated 
crop choices are based on estimated agricultural production functions for smallholder farmers in Malawi as well as assumed constraints regarding the cultivation of staple crops for subsistence purposes. Following a brief description of the Malawian agricultural context, we will explain the simulation approach, assumptions, and results.

\subsection{Institutional Context in Malawi Relevant to the Empirical Application}

There are a number of institutions that serve farmers in Malawi, including extension and other sources of agricultural information, credit sources, input and output markets, farmers unions, and social safety net programs. The density and quality of these institutions should increase farm productivity and the ability of farm household members to manage shocks to income, contributing to greater and more stable livelihoods.

- In this context, access to credit, extension services, and safety nets are of particular relevance to this paper since these three institutional avenues are central to managing agricultural risk. In terms of access to credit, in the 2010 LSMSISA household survey, just $16 \%$ of all households accessed some form of credit, from both formal and informal sources, indicating that access to credit is quite constrained. This is further supported by the fact that among those accessing credit, 57\% of loans came from neighbors/relatives/friends.

- In terms of extension services, despite a relatively large numbers of communities with agriculture extension officers, in 2010, information from the household survey indicates that just $21 \%$ of households received any extension advice in the Northern region, followed by $18 \%$ and $12 \%$ in Central and Southern regions, respectively. Beyond the limited reach of extension, Nkonya et al. (2015) also report that in Sub-Saharan Africa when extension advice is received it fails to provide advice on adaptation to climate change.

- Finally, concerning the Malawi Social Action Fund (MASAF), which provides a safety net to vulnerable households, in the 2010 survey $28 \%$ of villages surveyed had a MASAF program.

Without going into the detail of the functioning of these institutions, the picture that emerges from these statistics is one that highlights the limited access to information, credit, and safety nets for Malawian farmers. The challenges of managing risk faced by agricultural households are therefore numerous. The application presented here tries to provide new insights that would allow focusing potential efforts by policymakers interested in addressing agricultural risk management issues in Malawi.

Concerning insurance, in 2005, the World Bank, in close collaboration with Malawi's National Association of Small Farmers (NASFAM), developed an index- 
based crop insurance program, which led to 892 groundnut farmers purchasing weather-based crop insurance policies. During the 2006/2007 cropping season, the pilot expanded to 1710 farmers, with the inclusion of coverage for maize. A positive effect of the program was that, as the crop insurance contracts mitigated the weather risk associated with lending, local banks came forward to offer loans to insured farmers. However, what emerged from this pilot was that index-based weather insurance is not a panacea, since farmers face a broad spectrum of risk beyond just weather risk (Bryla and Syroka 2009). Furthermore, to be effective index-based weather insurance contracts require reliable, timely, and high quality weather data with a long historical record. More importantly from an institutional perspective, an improved enabling legal and regulatory framework is necessary for the expansion of any weather index insurance in Malawi. These challenges, combined with the often limited understanding of insurance, can lead to low adoption of insurance. We are aware of these challenges, and here we discuss weather index insurance as one possible tool in a portfolio of risk management options, as indicated by the theoretical model presented in the previous section.

\subsection{Background Information on Malawi for the Empirical Application}

Agriculture is the mainstay of the economy of Malawi accounting for about $34 \%$ of GDP, $85 \%$ of the labour force and $83 \%$ of foreign exchange earnings (Mucavele 2007). Smallholders account for $78 \%$ of the cultivated land and generate about $75 \%$ of Malawi's total agricultural output, indicating the predominance of the smallholder agricultural sector (Chirwa and Quinion 2005; Tchale 2009). Malawi is densely populated, with $84 \%$ of farmers practicing rainfed agriculture only, and more than $72 \%$ of the smallholder farms having an area of less than one hectare. Such conditions already make food self-sufficiency at the household level difficult, and the predicted impacts of climate change in Malawi are expected to primarily impact smallholder, rain dependent farmers (Denning et al. 2009).

The principal crops grown in Malawi are maize, tea, sugarcane, groundnut, cotton, wheat, coffee, rice and pulses. A significant feature of Malawi's agriculture is the dominance of maize in farming systems. It is estimated that more than $70 \%$ of the arable land is allocated to maize production (GoM 2006). According to Dorward et al. (2008), the share of farmers growing maize varies from $93 \%$ to $99 \%$ in the country's main regions. Although agriculture and maize are clearly very important to the livelihoods of most Malawians, their overall productivity performance raises serious concerns about long-term viability. The factors that are commonly cited as underlying low crop productivity include weather variability, declining soil fertility, limited use of improved agricultural technologies and sustainable land management practices, low/poor agricultural extension services, market failures, and underdevelopment and poorly maintained infrastructure (World Bank 2010). 
Of relevance to agricultural risk management in Malawi, the yield of crops is limited to differing degrees by water availability and temperature depending on the agroecological zone (see Fig. 1). A synthesis of climate data by the United Nations Development Program (McSweeney et al. 2012) indicated that in the period 1960 to 2006, mean annual temperature in Malawi increased by $0.9^{\circ} \mathrm{C}$. This increase in temperature has been concentrated during the rainy summer season (December February), and is expected to increase further. Long term rainfall trends are difficult to characterize due to the highly varied inter-annual rainfall pattern in Malawi, though such variability is expected to increase under climate change (McSweeney et al. 2012).

\subsection{Data and Estimated Production Functions}

We now turn our attention to simulations of smallholder Malawian farmer planting decisions and outcomes under a number of climate change and policy intervention scenarios. The relationships between input usage and yields for each crop and CSA technique, are estimated separately using multiple regressions with data from the Third Integrated Household Survey (IHS3 2012), which was conducted from March 2010 to March 2011 and implemented by the Malawian National Statistical Office (NSO) in collaboration with the World Bank. From this dataset we rely on information from $\sim 7800$ Malawian rural households covering $~ 18,500$ individual plots cultivated during the 2009-2010 agricultural season. While such estimates are made for all four agro-ecological zones (AEZs) in Malawi, this investigation focuses on Tropical Warm/Semiarid AEZ for which the most data are available (nearly 9000 plot observations). Crop specific production functions are estimated by regressing logged plot level yields on logged input usages and weather conditions. The use of logged values of yields and inputs in a linear framework is equivalent to assuming a Cobb-Douglas production function with a translog structure. As weather variables enter linearly (i.e.- not logged), they are treated as TFP shifters. The resulting estimated regression equations serve as the production functions for later simulation of farmer outcomes under various weather, price, information, and restriction scenarios. Table 1 presents the coefficient estimates from the 2009-2010 data for the Tropical Warm/Semiarid AEZ. These coefficients define the production functions used in the simulation of farmer planting decisions and outcomes.

Crop specific functions for variation in yields are also estimated through linear regressions of the standard deviation of yields between plots within the 768 Enumeration Areas on measures of the level and variation of rainfall and temperatures during the 2009-2010 growing season. The resulting estimated equations (one for each crop type) serve to simulate the variation in yields under scenario specific conditions.

As outlined in Table 1, agricultural inputs included in the estimation of production functions include seed quantity, fertilizer usage, days of labor, and land area of the plot. Weather conditions, which are used to estimate both the production and yield variation functions, include mean and standard deviation of temperatures and 


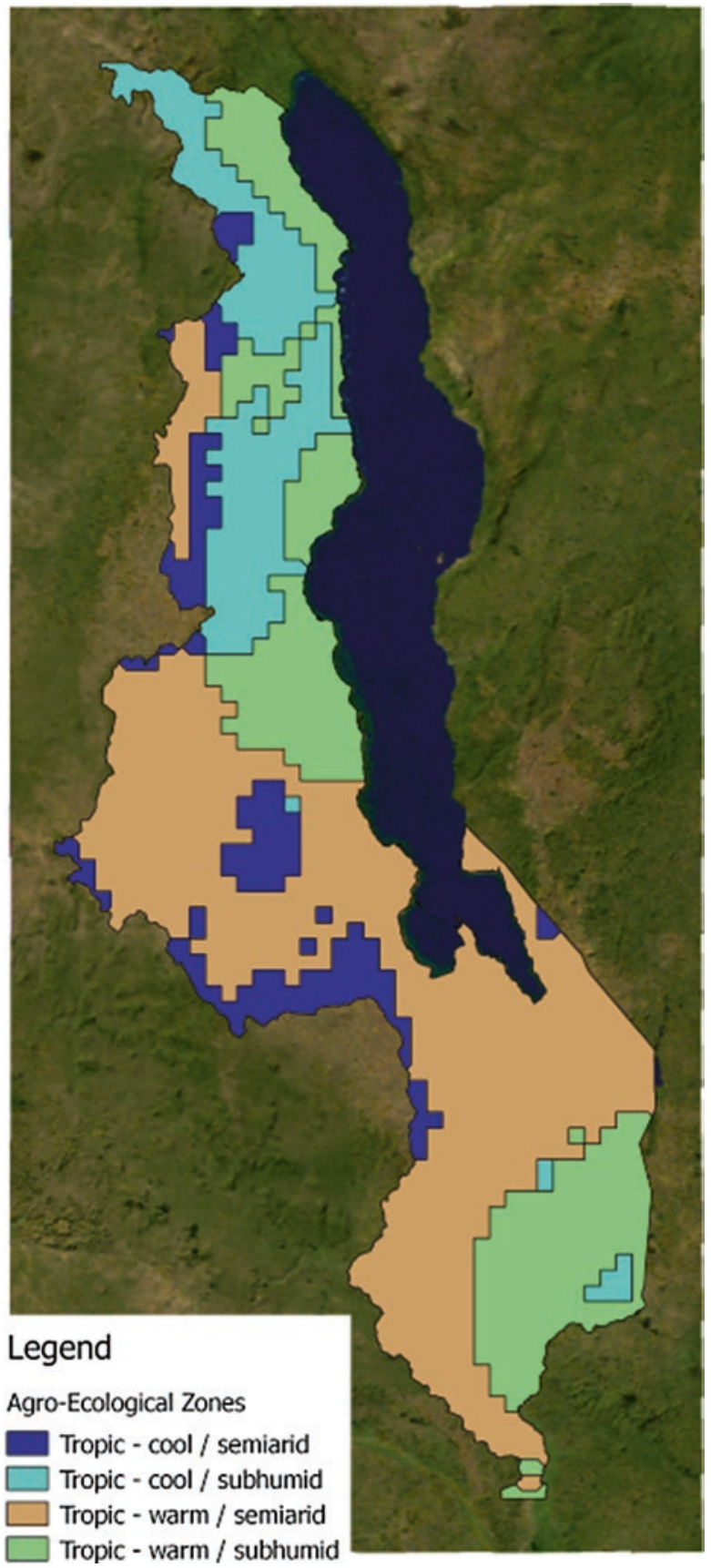

Fig. 1 Malawi agro-ecological zones 
Table 1 Coefficient estimates for production function by crop - dependent variable is logged yield

\begin{tabular}{|c|c|c|c|c|c|c|}
\hline & $\begin{array}{l}\text { Maize } \\
\text { local }\end{array}$ & $\begin{array}{l}\text { Maize } \\
\text { hybrid }\end{array}$ & $\begin{array}{l}\text { Groundnut } \\
\text { Chalimbana }\end{array}$ & $\begin{array}{l}\text { Groundnut } \\
\text { CG7 }\end{array}$ & Beans & $\begin{array}{l}\text { Pigeonpea } \\
\text { (nandolo) }\end{array}$ \\
\hline \multirow{2}{*}{$\begin{array}{l}\text { Seed } \\
\text { Quantity - } \\
\text { Logged } \\
(\mathrm{kg})\end{array}$} & 0.0288 & 0.0403 & 0.0745 & 0.062 & 0.18 & 0.164 \\
\hline & $(0.02)$ & $(0.02)$ & $(0.03)$ & $(0.02)$ & $(0.06)$ & $(0.03)$ \\
\hline \multirow{2}{*}{$\begin{array}{l}\text { Fertilizer } \\
\text { Usage - } \\
\text { Logged } \\
(\mathrm{kg})\end{array}$} & 0.0411 & 0.0453 & -0.0153 & 0.00131 & -0.0265 & 0.00514 \\
\hline & $(0.00)$ & $(0.00)$ & $(0.01)$ & $(0.01)$ & $(0.02)$ & $(0.01)$ \\
\hline \multirow{2}{*}{$\begin{array}{l}\text { Labor } \\
\text { Days - Logged } \\
\text { (days) }\end{array}$} & 0.161 & 0.0985 & 0.0715 & 0.175 & 0.0347 & 0.25 \\
\hline & $(0.04)$ & $(0.04)$ & $(0.06)$ & $(0.06)$ & $(0.14)$ & $(0.05)$ \\
\hline \multirow{2}{*}{$\begin{array}{l}\text { Cultivated } \\
\text { Area - Logged } \\
\text { (hectares) }\end{array}$} & 0.491 & 0.436 & 0.296 & 0.55 & 0.263 & 0.196 \\
\hline & $(0.04)$ & $(0.04)$ & $(0.06)$ & $(0.06)$ & $(0.14)$ & $(0.06)$ \\
\hline \multirow{2}{*}{$\begin{array}{l}\text { Mean } \\
\text { Temperature } \\
\text { (10-day mean) }\end{array}$} & -0.0702 & -0.17 & -0.0151 & 0.0546 & 0.0837 & 0.246 \\
\hline & $(0.03)$ & $(0.03)$ & $(0.06)$ & $(0.06)$ & $(0.11)$ & $(0.07)$ \\
\hline \multirow[t]{2}{*}{ SD Temperature } & -0.858 & -0.243 & -0.0946 & -0.155 & 0.253 & 0.928 \\
\hline & $(0.20)$ & $(0.20)$ & $(0.32)$ & $(0.31)$ & $(0.90)$ & $(0.28)$ \\
\hline \multirow{2}{*}{$\begin{array}{l}\text { Mean } \\
\text { Precipitation } \\
(\mathrm{mm} / 10 \text {-day } \\
\text { period) }\end{array}$} & 0.0178 & 0.036 & 0.0383 & 0.0314 & 0.0771 & -0.0511 \\
\hline & $(0.01)$ & $(0.01)$ & $(0.02)$ & $(0.01)$ & $(0.03)$ & $(0.01)$ \\
\hline \multirow{2}{*}{$\begin{array}{l}\text { SD } \\
\text { Precipitation }\end{array}$} & -0.0186 & -0.0573 & -0.0342 & -0.0327 & -0.0654 & -0.0239 \\
\hline & $(0.01)$ & $(0.01)$ & $(0.02)$ & $(0.02)$ & $(0.03)$ & $(0.02)$ \\
\hline \multirow[t]{2}{*}{ Constant } & 8.386 & 10.68 & 4.816 & 4.068 & 0.806 & -1.42 \\
\hline & $(0.91)$ & $(0.93)$ & $(1.55)$ & (1.59) & $(2.15)$ & $(1.67)$ \\
\hline
\end{tabular}

Notes: Standard errors reported in parenthesis. Significance of estimates is not taken into account when applying estimates in the simulation.

rainfall over 10-day periods during the growing season, and are observed for each enumeration area. The 2009-2010 rainy season therefore serves as the basis for defining the relationships between inputs, weather conditions, and yields. Additionally, the 2009-2010 growing season serves as the baseline period for weather conditions and all prices used in the simulations.

It is important to note also that the direct reliance of the model on data for the estimation of yield functions and input usages restricts the scope of crops and agricultural techniques that are considered in the simulations to those that are in wide use during the 2009-2010 Malawian growing season and that, more in general, characterize Malawi agricultural production. In particular, neither crop varieties nor cultivation practices that are particularly adapted to varying conditions under climate change are considered in the simulations because no basis for modelling the relevant relationships between inputs and outputs exists in the data, nor information 
on crop varieties. Practically, this approach assumes that crop and technique availability doesn't change in the simulated future and thus implicitly limits the scope of extension activities (when extension is considered) to the provision of information regarding growing conditions. ${ }^{8}$

\subsection{Simulation Model Assumptions}

Following the estimation of the production and yield variation functions using the 2009-2010 data, the simulation of farmer decisions and resulting outcomes for a future growing season are undertaken in two distinct stages. In the first, a representative farmer is faced with a planting decision based on known input prices, anticipated weather conditions, and known relationships between inputs, weather, and yields. ${ }^{9}$ This information, along with anticipated output prices is used by the farmer to maximize expected utility through decisions about which crops to plant and what, if any, CSA techniques to use. In the second stage, farmer outcomes are simulated based on crop and CSA choices and scenario specific weather conditions. The degree to which farmer expectation of weather conditions align (or not) with realized conditions serves as a measure of farmer information regarding climate change. Changes in the level of farmer "informedness" are the means through which extension informational programs can impact simulated farmer cropping choices and outcomes.

The representative farmer must choose between local and hybrid maize as a staple crop, and may also plant a cash crop for diversification purposes. The simulated diversification crops are all legumes and include Chalimbana Groundnuts, CG7 Groundnuts, Beans, and Pigeon Peas. The farmer is restricted to planting a minimum share of the chosen staple crop in order to ensure subsistence (which is not given an explicit utility or profit value in the simulations), and can choose up to one diversification crop to plant in addition to the staple (thus, planting 100\% staple crop is always an option).

For any combination of staple and diversification crop, the farmer also selects whether and which CSA techniques to apply to the growing of the staple crop. Specifically, the farmer chooses between soil and water conservation (SWC) techniques, legume intercropping, or both in these simulations. Each CSA technique modulates the impact of inputs and weather on yields of the staple (but not the

\footnotetext{
${ }^{8}$ It is worth noting that maize utilization in Malawi is largely linked to the fertilizers input subsidy program (FISP) which accounts for a limited range of varieties distributed but even accounting for varietal diversity the main distinction would still be linked to local versus hybrid maize utilization.

${ }^{9}$ Input and output prices, as well as the production and yield variance functions are not altered in any of the scenarios considered in this chapter, but are instead held fixed as observed in the 20092010 growing season.
} 
diversification crop, if any) in ways that are assumed to be understood (and thus taken account of) by the farmers.

As in our conceptual model, farmers are assumed to have a mean-variance utility function in net profits. They choose the crop mix (up to one staple and one diversification crop) and CSA technique usage by maximizing expected utility given anticipated weather and price conditions. As noted, farmers are allowed at most one diversification crop and, for simplicity, we limit our analysis to crop shares in 10\% increments. In the second stage of the simulation, net profits and total utility are calculated (using the same mean-variance utility function) using scenario-specific weather conditions.

Simulated utility levels - both for anticipated utility in stage 1 and realized utility in stage 2 - are simply the sum of the simulated net profit minus the simulated variance of revenues times the coefficient of absolute risk aversion. This mean-variance utility function is laid out explicitly below:

$$
\begin{gathered}
U=p_{1} \widehat{\text { yield }}_{1}+p_{2} \widehat{\text { yield }_{2}}-I P \cdot I \\
-A R A^{*}\left[p_{1}^{2} \operatorname{Var}\left(\widehat{\text { yield }_{1}}\right)+p_{2}^{2} \operatorname{Var}\left(\widehat{\text { yield }_{2}}\right)+2 p_{1} p_{2} \operatorname{cov}\left(\text { yield }_{1}, \text { yield }_{2}\right)\right]
\end{gathered}
$$

Above we see the simulated yield levels for the staple, $\widehat{\text { yield }}_{1}$, and diversification crop, $\widehat{\text { yield }} 2$, multiplied by their respective output prices, $p_{1}$ and $p_{2}$. From this simulated revenue, the dot product of the vectors of input prices, $I P$, and input usages, $I$, is subtracted to yield net profits. The second line of the equation is the variance portion of the utility function, discounted by the coefficient of absolute risk aversion. The variance of revenues (equivalent to the variance of profits since input prices are non-stochastic) is simply the simulated variance of yields from the two

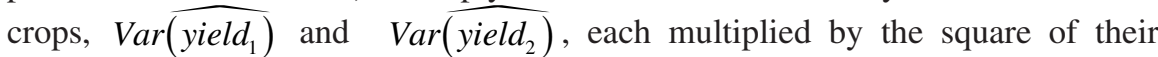
respective output prices, plus the covariance correction term $2 p_{1} p_{2} \operatorname{Cov}$ (yield , yiel $\left.d_{2}\right){ }^{10}$ The between-crop covariance term is estimated directly from yields in the 2009-2010 data.

The representative farmer is simulated making planting decisions for a single average sized plot of 0.74 hectares and is assumed to apply mean input levels for each crop planted and CSA technique utilized. Labor costs for different crop choices and CSA usages are included in the cost calculation used by the farmer for planting decisions but are omitted from the simulation of realized utility, as most labor is provided without monetary cost (by family, friends, or for an in-kind payment). Finally, a coefficient of Absolute Risk Aversion of 0.00016 is assumed, which implies a coefficient of Relative Risk Aversion of approximately 1.5 for the representative farmer. The modelled level of risk aversion is informed by the estimated

${ }^{10}$ This summing procedure is simply following the rules for adding variances, namely:

$$
\operatorname{Var}(a X+b Y)=a^{2} \operatorname{Var}(X)+b^{2} \operatorname{Var}(Y)+2 a b \operatorname{cov}(X, Y)
$$


risk aversion parameters of De Brauw \& Eozenou (2014) for Mozambican farmers, while taking into account the lower average incomes of Malawians.

\subsection{Climate Scenarios}

Three climate change scenarios are considered in these simulations. These include a "No Climate Change" scenario under which weather conditions remain at baseline, that is as observed in the 2009-2010 rainy season, a "Mid-line Climate Change" scenario under which mean temperature, standard deviation of temperature and standard deviation of rainfall are all increased by $10 \%$ from baseline, and a "High Climate Change" scenario under which the levels of these three weather variables are increased by $20 \%$ from baseline. Due to the uncertainty of the effects of climate change on rainfall levels in Malawi, we do not simulate changes in mean rainfall as part of our climate change scenarios. ${ }^{11}$

Observed price levels in the 2009-2010 data are used for both inputs and outputs under all three climate change scenarios, thus the general equilibrium effects of climate change on market prices are not considered by this analysis. ${ }^{12}$

\section{Simulation Results}

As described earlier, we will simulate the impacts of insurance and extension under a variety of climate change scenarios. For the purposes of simulation, the function of the extension will be limited to providing farmers with information about changing weather conditions due to climate change. This is akin to extension activities only impacting $m$ in the conceptual model. While it is likely that extension services would be much broader in practice, the simulation of such effects is left for later work. Since the effectiveness of these two policy instruments will be inter-connected when extension is influencing farmer perceptions about climate change and thus the returns to insurance acquisition, we also present some stylized simulations where both are implemented simultaneously. Throughout, we contemplate two distinct assumptions regarding constraints on staple crop cultivation for subsistence purposes - a $50 \%$ and a $70 \%$ requirement - in part to illustrate the importance of crop diversification as a potential response to increased weather volatility and also to

\footnotetext{
${ }^{11}$ See McSweeney et al. (2012) for more information on the anticipated impacts of climate change on Malawi.

${ }^{12}$ Given the high proportion of subsistence farmers in Malawi, increased output prices due to increased scarcity under climate change are likely to be detrimental on net, and thus farmer outcomes simulated in a general equilibrium framework would likely be associated with lower levels of overall utility than those presented here.
} 
demonstrate the additional value of information for farmers that are less constrained - by subsistence requirements or otherwise - in their planting decisions.

\subsection{Insurance}

Insurance in this context is assumed to be rainfall index insurance with a predetermined payout amount that is varied in certain simulations to model different levels of insurance coverage. Payouts are received if rainfall is below a pre-specified level, fixed in our simulations at the 30th percentile of the rainfall distribution at baseline. Universal participation in the rainfall insurance program is assumed when the program is available, and premiums are assumed to be zero (or covered by the government or other outside institution). ${ }^{13}$

We begin by looking at the impacts of insurance coverage on farmer decisions and outcomes. Panels a \& b of Fig. 2 report the results of simulations in which the payout amount for rainfall insurance is varied between zero and $6000 \mathrm{MWK}$ (which is slightly above $100 \%$ of expected net profits under baseline conditions) for each of the three climate change scenarios with a $70 \%$ staple requirement (Fig. 2a) and a $50 \%$ staple requirement (Fig. 2b). As the level of payout increases we see the simulated average total utility rise in all three climate change scenarios under both staple constraints. These simulations assume farmers are unaware of the changes to weather conditions under the climate change scenarios, and thus we observe no differences in crop choice or CSA usage between scenarios. The changes in weather conditions do however affect farmer outcomes as illustrated by the lower utilities simulated under the Mid-line and High Climate Change scenarios. The greater the difference between farmer-anticipated and realized weather conditions, the larger the loss of utility to farmers.

It is worth noting that under more extreme climate change scenarios, the variance of rainfall (but not the mean) increases. This slightly increases the likelihood of payout at the 30th percentile of baseline rainfall (as well as at all other rainfall trigger levels below the 50th percentile), but this change is not significant enough to be easily distinguished in the presented figures as the effects of climate change on production greatly outweigh the effects on the probability of insurance payout. Nonetheless, farmer outcomes improve slightly more under the Mid-line Climate Change scenario than under the No Climate Change scenario and under the High Climate Change scenario compared to the Mid-line Climate Change scenario because of the increase in likelihood of a payout.

Comparing outcomes under the more and less restrictive staple requirements, we see higher levels of diversification when the staple requirement is relaxed, but that greater diversification into a cash crop (in this case beans) opens the farmer up to greater harm under climate change.

\footnotetext{
${ }^{13}$ Mapping this insurance policy and subsequent simulations into the conceptual model involves setting $c_{\psi}=0$ and varying $\psi$ exogenously.
} 


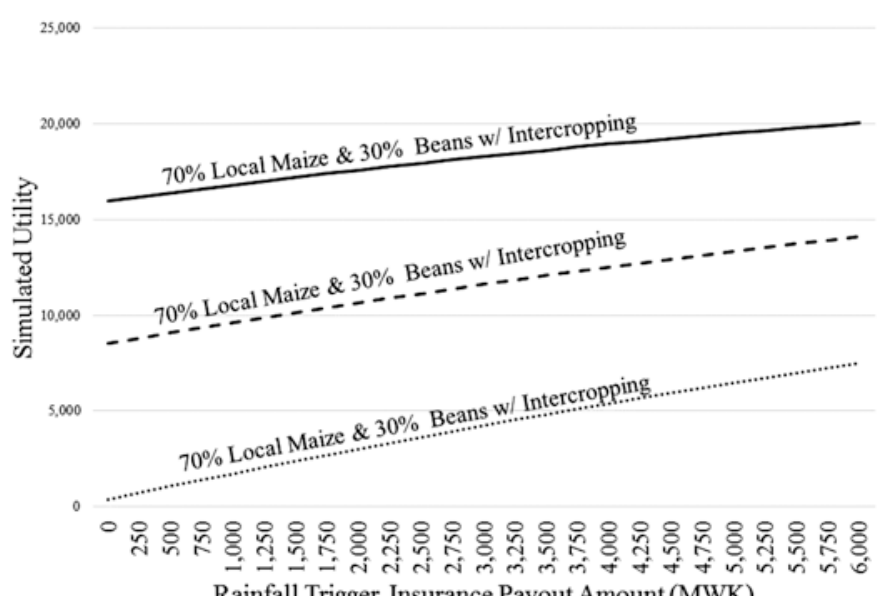

Rainfall Trigger Insurance Payout Amount (MWK)

—No Climate Change - - Mid-Line Climate Change …... High Climate Change

b

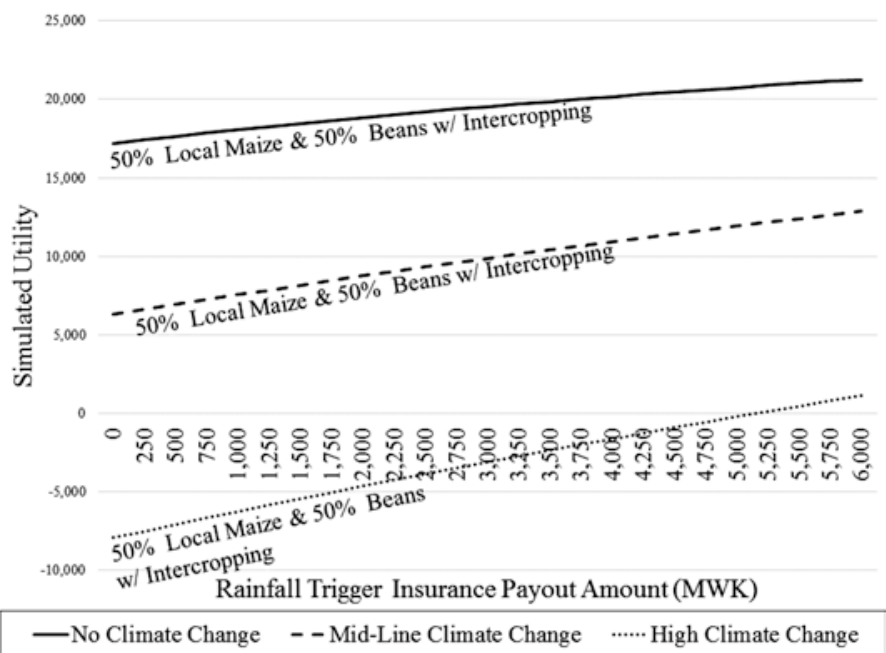

Fig. 2 (a) Simulated Utility by Insurance Payout, Unanticipated Climate Change - 70\% Staple Requirement. Notes: Simulations are based on coefficient estimates and baseline parameter values from the Tropical Warm/Semiarid Agro-ecological Zone, which is the AEZ in Malawi for which the most data are available. Simulated profits under baseline conditions are equal to $5934 \mathrm{MWK}$, thus the maximum insurance payout simulated here amounts to a full replacement of baseline profits. All utility levels are normalized via the addition of 30,000 units. Crop Choice and CSA usage does not differ between scenarios because climate change is unanticipated. (b) Simulated Utility vs. Insurance Payout, Unanticipated Climate Change $-50 \%$ Staple Requirement. Notes: Simulations are based on coefficient estimates and baseline parameter values from the Tropical Warm/Semiarid Agro-ecological Zone, which is the AEZ in Malawi for which the most data are available. Simulated profits under baseline conditions are equal to $5152 \mathrm{MWK}$, thus the maximum insurance payout simulated here amounts to more than a full replacement of baseline profits. All utility levels are normalized via the addition of 30,000 units. Crop Choice and CSA usage does not differ between scenarios because climate change is unanticipated 
In Fig. 3, the payout amount of the rainfall trigger insurance is again varied (and the trigger level is still held fixed at the 30th percentile of baseline rainfall), only this time farmers are informed about the changes in weather conditions under the climate change scenarios and can adjust their planting decisions accordingly. This allows farmers to adopt additional CSA techniques in the face of harsher weather conditions, and also to switch diversification crop from Beans to Groundnut CG7 (which is specifically noted for its drought tolerance, see Subrahmanyam et al. 2000). These adaptations on the part of the farmer lead to utility outcomes under climate change that are much more similar to the baseline outcomes than those achieved when changes in weather conditions were unanticipated. As weather variation increases, that is, as we move from the No Climate Change scenario to the Mid-line and on to the High Climate Change scenario, we see planting decisions moving toward greater adoption of CSA techniques, consistent with Eq. 11 in the conceptual model as well as the results of Arslan et al. (2013). ${ }^{14}$

Comparing Panels a \& b in Figs. 2 and 3, we see again that the relaxation of staple requirements leads to further diversification and poorer outcomes under climate change. These results suggest that farmers that are currently somewhat better off (and thus are less constrained by subsistence requirements to plant a staple crop) are more susceptible to harm under unanticipated climate change. While information regarding climate change (i.e.- when the changes in weather conditions are anticipated) improves outcomes for all farmers under the climate change scenarios, this improvement is most dramatic when staple requirements are less stringent, suggesting a higher value of information for less constrained farmers. Put another way, without information on climate change, shifts in weather conditions have greater potential to harm farmers that are less constrained. Without good information on climate change, this effect would tend to increase subsistence constraints in successive years as farmers that began with more flexibility will tend to face greater harm from unanticipated changes in weather conditions. Finally, it is notable that better information regarding weather conditions (that is comparing Figs. 2 and 3) leads to additional uptake of CSA techniques, providing a concrete example of increased farmer adaptive behavior in the face of climate change following a risk management intervention.

\subsection{Extension and Information Provision}

Given the results in Figs. 2 and 3, we now turn to a more direct examination of how more information about changing weather conditions under climate change might impact farmer choices and outcomes. Panels a and b of Fig. 4 demonstrate the results of bringing farmer expectations regarding weather conditions closer in line

\footnotetext{
${ }^{14} \mathrm{We}$ do not however see increasing diversification in response to growing weather variability as predicted by Equation 13. Likely reasons for this are discussed in Section IV.B below in the context of better information regarding variability.
} 
a

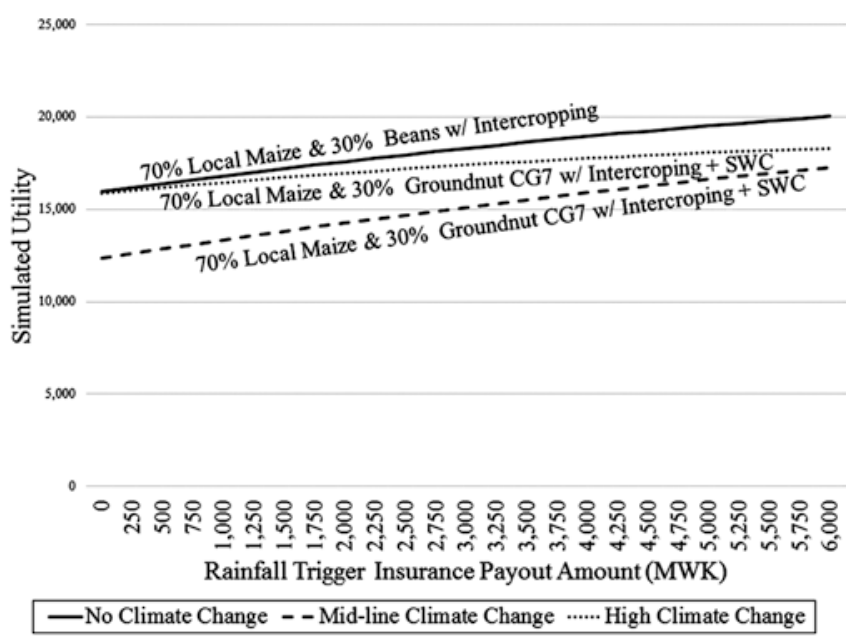

b

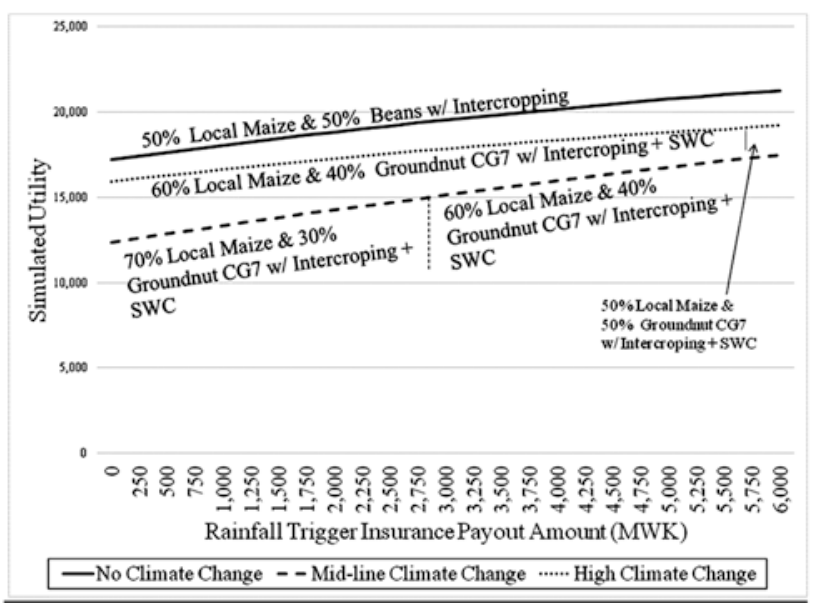

Fig. 3 (a) Simulated Utility by Insurance Payout, Anticipated Climate Change - 70\% Staple Requirement. Notes: Simulations are based on coefficient estimates and baseline parameter values from the Tropical Warm/Semiarid Agro-ecological Zone, which is the AEZ in Malawi for which the most data are available. Simulated profits under baseline conditions are equal to 5934 MWK, thus the maximum insurance payout simulated here amounts to a full replacement of baseline profits. All utility levels are normalized via the addition of 30,000 units. (b) Simulated Utility by Insurance Payout, Anticipated Climate Change - 50\% Staple Requirement. Notes: Simulations are based on coefficient estimates and baseline parameter values from the Tropical Warm/Semiarid Agro-ecological Zone, which is the AEZ in Malawi for which the most data are available. Simulated profits under baseline conditions are equal to $5152 \mathrm{MWK}$, thus the maximum insurance payout simulated here amounts to more than a full replacement of baseline profits. All utility levels are normalized via the addition of 30,000 units 
a

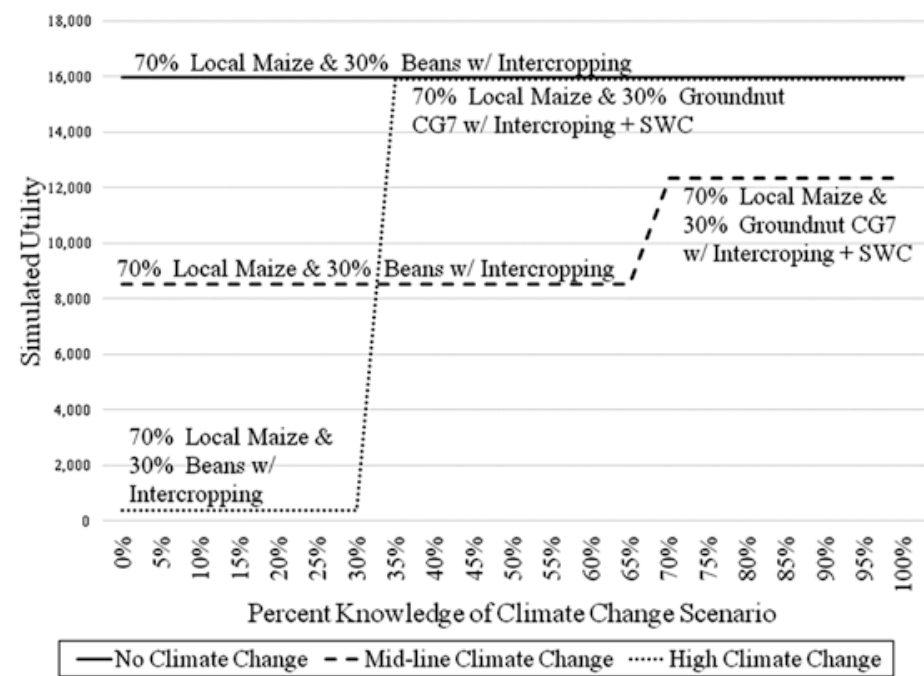

b

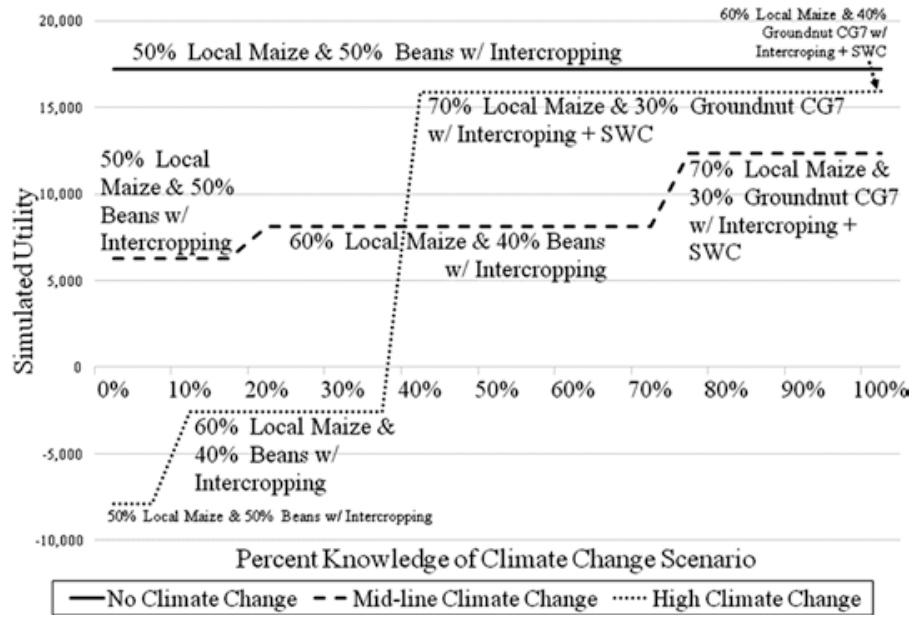

Fig. 4 (a) Simulated Utility by Informedness Regarding Climate Change - 70\% Staple Requirement. Notes: Simulations are based on coefficient estimates and baseline parameter values from the Tropical Warm/Semiarid Agro-ecological Zone, which is the AEZ in Malawi for which the most data are available. All utility levels are normalized via the addition of 30,000 units. Crop Choice and CSA usage does not change under the No Climate Change scenario because weather conditions conform to farmer's expectations. (b) Simulated Utility by Informedness Regarding Climate Change $-50 \%$ Staple Requirement. Notes: Simulations are based on coefficient estimates and baseline parameter values from the Tropical Warm/Semiarid Agro-ecological Zone, which is the AEZ in Malawi for which the most data are available. All utility levels are normalized via the addition of 30,000 units. Crop Choice and CSA usage does not change under the No Climate Change scenario because weather conditions conform to farmer's expectations 
with the scenario conditions that drive yields. Partial information may capture either incomplete penetration of information provision (i.e. some share of perfectly informed farmers make for a representative farmer that is partially informed), imperfect information regarding the climate change scenario that farmers are encountering, or some combination of the two. However, since we simulate outcomes for a single "representative farmer", rather than all farmers on average, the simulations reflect an improving quality of information, such that the information the farmer relies on increasingly reflects the true conditions of the climate scenario that will determine yield outcomes. Over time, the smooth evolution of farmer expectations toward conditions under climate change could arise from straightforward Bayesian updating.

Under the No Climate Change scenario in Panels a \& b of Fig. 4, we see that increased information has no effect on planting decisions or outcomes because there is no deviation between farmers' baseline expectations and realized conditions (in effect, farmers are fully informed at baseline). However, when conditions do deviate from past levels - as they do under the Mid-Line and High Climate Change scenarios - we see that more information does drive different crop and CSA usage decisions. That is to say that farmer decisions change when farmer expectations about conditions deviate from baseline to the degree that another crop choice/CSA combination yields higher total utility. Specifically, as informedness regarding changing weather conditions increases, we see the adoption of SWC techniques - in addition to legume intercropping - and the planting of CG7 Groundnuts, which are high yielding and better suited to the weather conditions under climate change than Beans. Importantly we see that farmer outcomes improve as they are provided with additional information, and that the value of information increases as realized weather conditions deviate further from baseline expectations (that is, under scenarios in which climate change is more extreme).

Bringing expectations regarding weather conditions in line with the new realities under climate change is akin to increasing $m$ in the conceptual model. In response we see increased CSA usage as predicted by Eq. 15, but we generally see a fall in the level of the diversification crop planted. This apparent contradiction with the predictions of Eq. 17 is likely explained by better yields of local maize under climate change conditions relative to the cash crops. In our simplified conceptual model, diversification only reduces yield variability, but in our empirical context it can also lower the yields of cash crops relative to the staple, potentially increasing the level of staple planted.

Returning to the simulation results, we again see that the loosening of staple requirements weakly increases the usage of diversification crops under all scenarios. Additionally, farmers move away from baseline planting behaviors and achieve higher profits/utility with less information when they have a wider range of crop combination possibilities under the less restrictive staple requirements. This illustrates that farmers are better able to make use of partial information on climate change when they are less constrained by subsistence requirements. This point is particularly important given that perfect information on future weather conditions 
cannot be provided in the real world, so any information will necessarily be partial information.

\subsection{Insurance and Extension}

Tables 2 and 3 examine the potential impacts of insurance and information provided in concert on farmer decisions under the Mid-line and High Climate Change scenarios respectively. Results are not presented for the No Climate Change scenario as information regarding climate change is of no value in that case. Moreover, we only present results under the 50\% staple requirement in order to focus attention on the effects of changes in information and insurance coverage rather than the staple constraint. Simulated utility levels are not presented in these tables, but utility levels weakly increase as the levels of information and insurance payout increase (that is as we move toward the bottom right of each table). It is worth noting that the top and bottom rows of Tables 2 and 3 correspond to the dashed and dotted lines in Figs. $2 b$ and $3 \mathrm{~b}$, while the first columns of the tables correspond to the dashed and dotted lines respectively in Fig. $4 \mathrm{~b}$.

Tables 2 and 3 show, without exception, that the amount of land dedicated to cash crops weakly increases as the level of insurance coverage increases. This finding is consistent with the conclusions of Collier et al. (2009), who argue that weather index insurance can, if appropriately designed, be used to facilitate farmer adaptation to climate change. These results suggest that government or donor assistance could be justified, and it should focus on funding the start-up costs of developing weather insurance markets and addressing the catastrophic layer of risk.

Turning to the effects of increased information regarding climate change, we see consistent switching from Beans as a cash crop to Groundnut CG7 which is better adapted to the climate change impacted weather conditions. Similarly, we see the wider adoption of SWC techniques as better information on the extent of climate change is made available to the farmers. Both these characterizations hold across insurance coverage levels, and suggest greater adaptation in the face of greater anticipated change, no matter the level of insurance coverage.

It is also worth noting that in a number of cases where insurance payouts are high and climate change expectations are moderate, hybrid maize will be planted rather than the local maize that is more typical. It would appear that these cases represent scenarios when the farmer, relieved of some downside risk by high insurance coverage, seeks to take advantage of the upside potential of hybrid maize. This response proves ex post problematic since hybrid maize is more sensitive to weather variability. Once the full extent of the changes in weather conditions due to climate change are revealed, the farmer returns to more conservative cropping choices and the disincentivizing impacts of insurance coverage on adaptation disappear. These results, however, should be interpreted in light of the data limitation of the study as well as the characteristics of Malawian agriculture. As already pointed out, the IHS3 


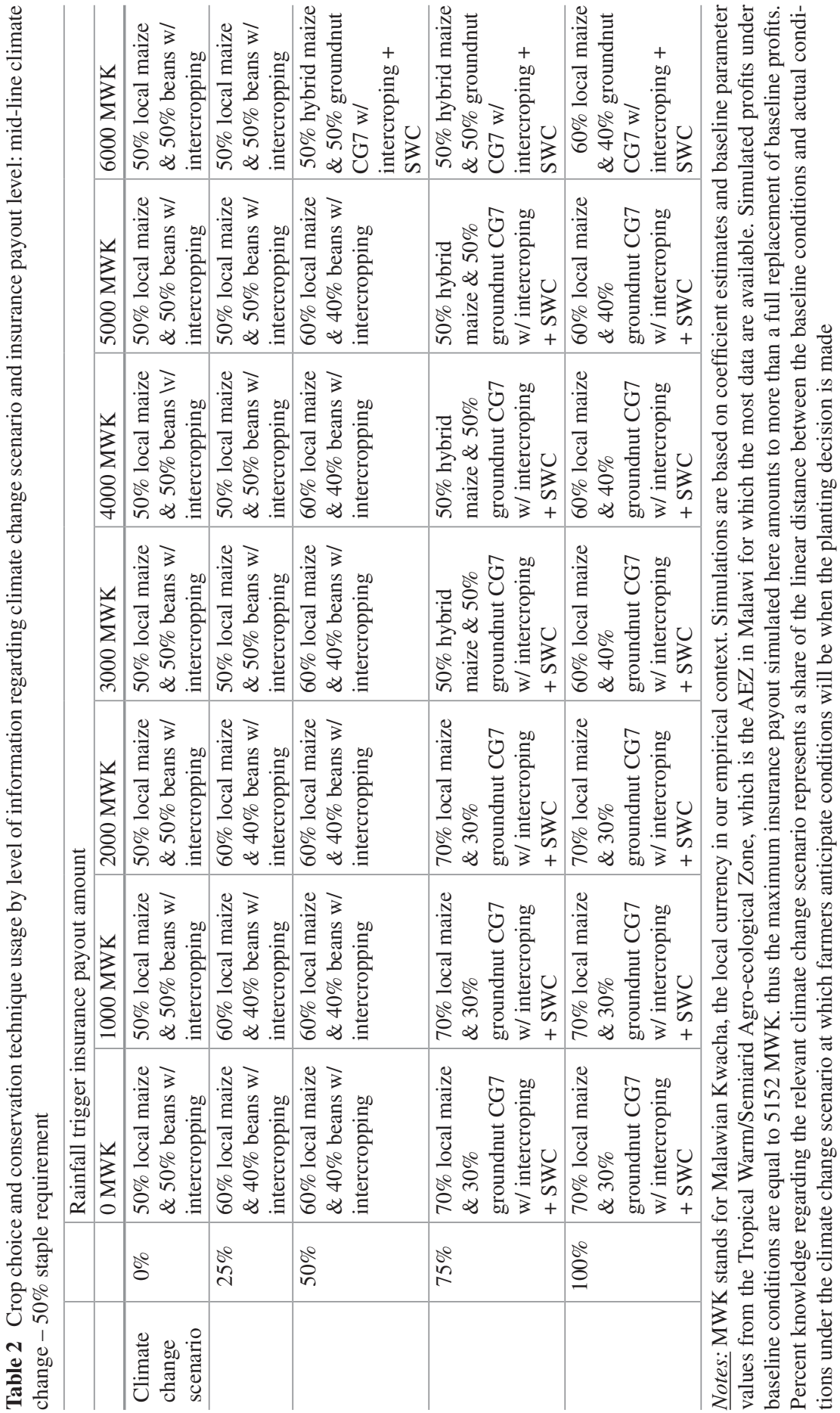




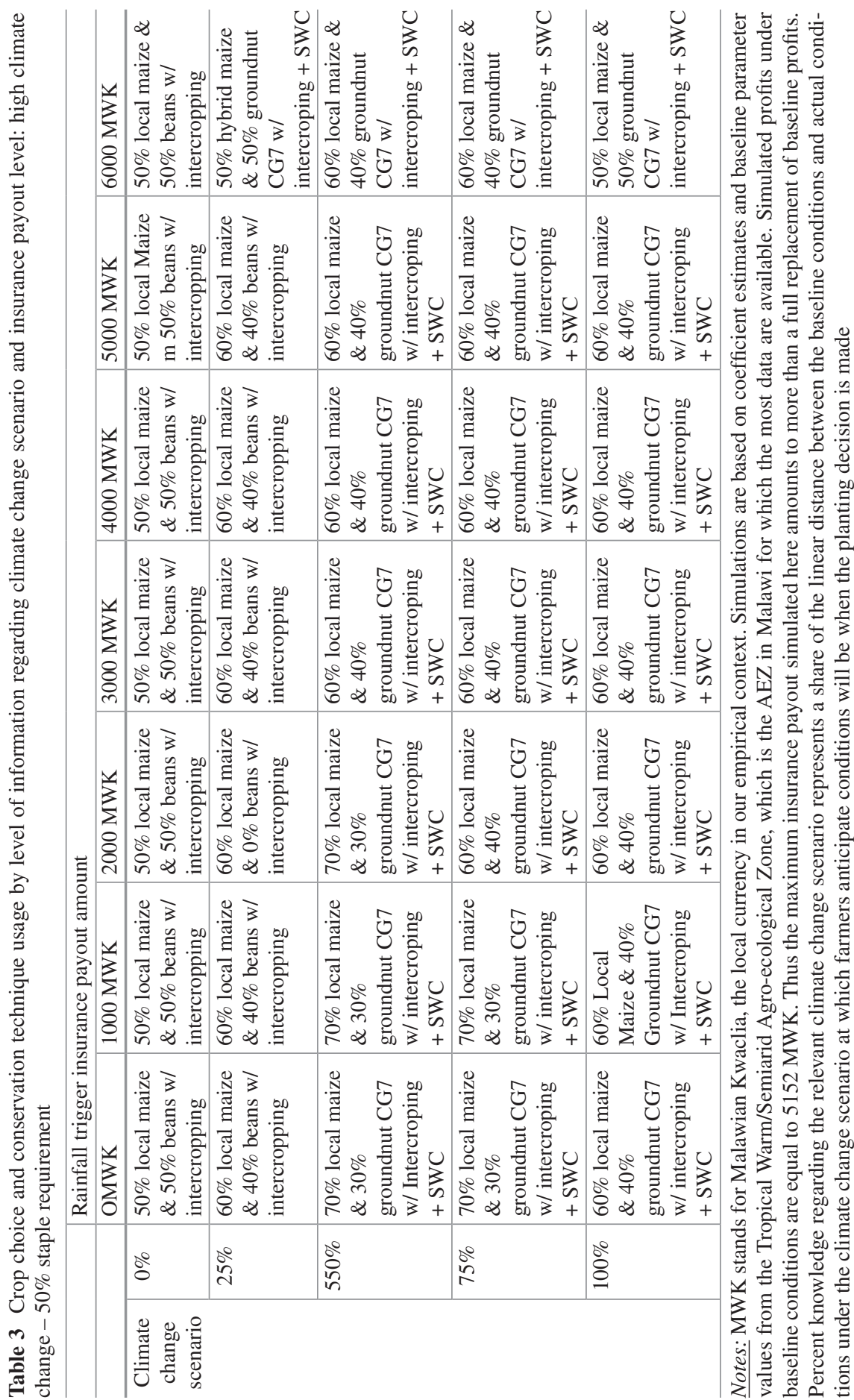


data used to model the relationships between input usage and maize yields do not allow to further distinguish between specific hybrid varieties including those that can be specifically adapted to climate change conditions. Moreover, Malawi in not a country of origin for the crop, which implies that genetic diversity is rather low compared to traditional maize domestication countries. ${ }^{15}$

\section{Conclusions and Policy Implications}

This chapter ventures into key support services that are explicitly addressed and contemplated in the Agriculture Sector Wide Approach (ASWAp) of Malawi- the national policy program of the country- namely: (1) technology generation and dissemination (whereby a key role is precisely identified for weather forecasting) and (2) institutional strengthening (including insurance) and capacity building.

The conceptual model built was also driven by results of an evidence base project that has been conducted in Malawi between 2012 and 2015 (FAO and GoM 2015). Results of the study indicate that:

(a) weather variability is a key factor determining which strategies will work across different locations in Malawi for agricultural practices, types of crops and diversification strategies suggesting explicitly that "using weather data in planning any agricultural and food security intervention" would be highly advisable.

(b) Improving communication of information and tailoring extension services to local conditions (including weather variability) is likely to increase adoption rates of different crops and agricultural practices as well as farm incomes across the country, therefore a stronger investment should be made to strengthen extension based service.

(c) In terms of risk management instruments available to farmers, no insurance exists in the country and as such insurance schemes and simulations could be examined in more depth as part of the agricultural risk management portfolio of options provided by policymakers.

As a result, the chapter built an empirical model, which aimed at advancing the state of knowledge on the options and choices between diversification and land management practices, through the presence or absence of institutional support provided by insurance and extension in the form of awareness of climate scenarios. Different potential welfare outcomes for agricultural households are, hence, investigated and examined as a result of the model. A third key institution, access to credit, is indirectly addressed through the implication of analysis conducted and results obtained.

\footnotetext{
${ }^{15}$ We nevertheless recognize room for improvement in our analysis as additional information may become available from the new wave of the IHS (IHS4) that the World Bank is currently implementing in Malawi.
} 
The conceptual model developed highlights that the interaction, in addressing risk, between diversification and land management complicates the role of policy levers and their impact. The model simulates the impacts of weather index insurance and extension under a range of climate change scenarios for two levels of staple requirements.

The empirical application, which presents results for farmers in the tropical warm/semi-arid AEZ of Malawi, builds on the conceptual model by estimating production functions and yield variation functions for different crops, and then simulating the outcome of farmer decisions.

As a first result, the crucial role played by extension, although in this model simply limited to climatic scenarios, is confirmed by the simulations, indicating that more information on climatic variables and their impact on yields can drive farmers to choose different crops, as well as different and more sustainable land management practices (SLM). It is interesting to note that among the SLM the main role is played by Soil and Water Conservation structures, confirming findings reported by FAO and GoM (2015), which suggested that "in areas where there is high and increasing variability of rainfall and higher aridity, the evidence indicates that sustainable land management practices such as soil and water conservation, legume rotation or intercropping and agroforestry (fertilizer tree systems) are more productive than conventional practices".

The important implication of this finding is that farmer welfare outcomes, driven by diversification of crop and adoption of SLM, improve as they are provided with additional information, and that the value of information increases as realized weather conditions deviate further from baseline expectations (that is, under scenarios in which climate change is more extreme). These results highlight how the value of information is higher for farmers that are less restricted in their planting choices, since they have a broader scope to adapt, suggesting important implications also with regard to access to other seed crops via credit.

Comparing outcomes under the more and less restrictive staple requirements, we see higher levels of diversification when the staple requirement is relaxed, but that greater diversification into a cash crop opens the farmer up to greater losses under climate change when this is not anticipated, suggesting that farmers that are currently somewhat better off (and thus are less constrained by subsistence requirements to plant a staple crop) are more susceptible to unanticipated climate change. While information regarding climate change (i.e. when the changes in weather conditions are anticipated) improves outcomes for all farmers under the climate change scenarios, this improvement is most dramatic when staple requirements are less stringent.

Moving to the role of insurance, it is important to note that the insurance instrument we analyzed is triggered by rainfall level and not by realized losses, as such the insurance parameters tend to not affect the cropping and land management practices adopted. This is important to avoid inhibiting adaptation measures. However, this may not always be the case in practice since diversification and management practices may differ from insurance in the way they affect a risk profile. Insurance will exclusively reduce downside risk whereas diversification and land management 
practices may reduce both downside and upside risk. Indeed we observe that in the case where farmers anticipate climate change, as the insurance payout amount increases there is a switch in the level of diversification under the more pronounced climate change scenario. Interestingly this effect is in the direction of greater diversification towards cash crops. This result is in line with literature that claims that a lack of access to insurance leads to a lower likelihood of farmers adopting new technologies (Feder et al. 1985; Antle and Crissman 1990). It is also confirmed by results from Asfaw et al. (2015), which suggest that policy interventions as well as insurance and credit scheme need to be prioritized taking households exposure to climatic risk into account and enabling farmers to pursue choices and diversify their portfolio of choices, for crop and income, so to reduce their vulnerability to poverty. This is suggested in our case, through the mechanism in play such that, as insurance reduces downside risk, farmers have an incentive to invest in higher risk and higher returns activities.

Last but not least, our simulations further suggest that extension and weather index insurance are complementary in the Malawian context, both leading to greater levels of adaptation and improved farmer welfare.

Farming is a risky enterprise and one that will only become riskier under climate change. While our analyses have highlighted the important role that extension and insurance can play in better managing that risk, limited financial resources will require governments to carefully weigh the costs and benefits of each strategy in the design of national or subnational policies. Although we did not explore it here, extension, in the form of information on climate change impacts, is likely to affect the budgetary outlays for any subsidized weather index insurance by helping in its design. The general conclusion is therefore that priority should be given to providing accurate and useful weather and climate information to farmers, as well as clear explanation of its implications in terms of adaptation options. Insurance, although not an adaptation strategy per se, can help in the adaptation process if appropriately designed to minimize the moral hazard that may attend insurance schemes that incentivize additional risk taking.

\section{References}

Antle, J. M. and C. C. Crissman (1990), Risk, Efficiency, and the Adoption of Modern Crop Varieties: Evidence from the Philippines. Economic Development and Cultural Change, 38(3): 517-537.

Antón, J. A. Cattaneo, S. Kimura, J. Lankoski (2013) Agricultural risk management policies under climate uncertainty. Global Environmental Change, Available online 10 September 2013., http://dx.doi.org/10.1016/j.gloenvcha.2013.08.007

Arslan, A., McCarthy, N., Lipper, L., Asfaw, S. and Cattaneo, A. (2013). Adoption and intensity of adoption of conservation farming practices in Zambia. Agriculture, Ecosystems and Environment, In Press, Available online 1 October 2013.

Asfaw, S., Mc Carthy, N., Paolantonio, A., Cavatassi, R., Amare, M., Lipper, L. (2015), "Livelihood diversification and vulnerability to poverty in rural Malawi". FAO-ESA Working Paper No. 15-02, August 2015. 
Bryla, E. and J. Syroka (2009) Micro- and meso-level weather risk management : deficit rainfall in Malawi. Experiential briefing note. Washington DC ; World Bank.

Chirwa, P. and Quinion, A. (2005). Impact of soil fertility replenishment agroforestry technology adoption on the livelihoods and food security of smallholder farmers in central and southern Malawi, in Sharma, P and Abrol, V (eds.) 'Crop Production Technologies', InTech, Rijeka, Croatia.

Collier, B., J. R. Skees and B. J. Barnett (2009), "Weather Index Insurance and Climate Change: Opportunities and Challenges in Lower Income Countries." Geneva Papers on Risk and Insurance - Issues and Practice 34:401-424., July.

De Brauw, Alan, and Patrick Eozenou. "Measuring risk attitudes among Mozambican farmers." Journal of Development Economics 111 (2014): 61-74.

Denning G, Kabambe P, Sanchez P, Malik A, Flor R, Harawa, R, Nkhoma, P, Zamba, C, Banda, C, Magombo, C, Keating, M, Wangila, J and Sachs, J (2009). Input subsidies to improve smallholder maize productivity in Malawi: Toward an African green revolution. PLoS Biology, 7(1): 2-10.

Deressa, T.T. and Hassan, R.H. (2010). Economic Impact of Climate Change on Crop Production in Ethiopia: Evidence from Cross-Section Measures. Journal of African Economies 18(4):529-554.

Dorward, A., Chirwa, E., Boughton D., Crawford, E., Jayne, T., Slater, R., Kelly, V., and Tsoka, M., (2008). Towards Smart Subsidies in Agriculture? Lessons from Recent Experience in Malawi, Natural Resource Perspectives 116: Overseas Development Institute, London, UK

Feder, G., R. Just, and D. Zilberman (1985), Adoption of Agricultural Innovations in Developing Countries: A Survey. Economic Development and Cultural Change, 33(2): 255-298.

Food and Agriculture Organization of the United Nations (FAO) and Government of Malawi (GoM) (2015), A Strategic Framework for Climate Smart Agriculture in Malawi, unpublished.

Government of Malawi (GoM) (2006). Malawi growth and development strategy 2006-2011: Ministry of Economic Planning and Development: Lilongwe, Malawi.

Graff-Zivin, J., \& Lipper, L. (2008). Poverty, risk, and the supply of soil carbon sequestration. Environment and Development Economics 13(03), 353-373.

Heltberg, R., P. B. Siegel, and S. L. Jorgensen. 2009. "Addressing human vulnerability to climate change: Toward a 'no-regrets' approach." Global Environmental Change 19(1): 89-99.

Heltberg, R. and Tarp, F. (2002). Agricultural Supply Response and Poverty in Mozambique. Food Policy 27: 103-124.

IHS3 (2012). Household socio-economic characteristics report. National statistical office, Lilongwe, Malawi.

Just, R. E., \& Pope, R. D. (1978). Stochastic specification of production functions and economic implications. Journal of Econometrics, 7(1), 67-86.

Kassie, M., Pender, J., Yesuf, M., Kohlin, G., Bluffstone, R. A. and Mulugeta, E. (2008). Estimating returns to soil conservation adoption in the northern Ethiopian highlands, Agricultural economics, 38: 213-232.

Markowitz H. (1987). Mean-Variance Analysis In Portfolio Choice And Capital Markets, Blackwell, Cambridge., Mass. and Oxford.

McSweeney, C., New, M. \& Lizcano, G. 2012. UNDP Climate Change Country Profiles: Malawi.. Available: http://country-profiles.geog.ox.ac.uk/

Mendelsohn, R. (2010), Agriculture and economic adaptation to agriculture, COM/TAD/CA/ ENV/EPOC(2010)40/REV1.

Meyer, J. (1987). Two-moment decision models and expected utility maximization. The American Economic Review, 421-430.

Mucavele, F. G. (2007), True Contribution of Agriculture to Economic Growth and Poverty Reduction: Malawi, Mozambique and Zambia Synthesis Report. Food, Agriculture and Natural Resource Policy Analysis Network.

Nkonya E., F. Place, E. Kato, and M. Mwanjololo. 2015. Climate Risk Management Through Sustainable Land Management in Sub-Saharan Africa. In R. Lal B. Singh, D. Mwaseba, 
D. Kraybill, D. Hansen and L. Eik (eds.), Sustainable Intensification to Advance Food Security and Enhance Climate Resilience in Africa, Springer International Publishing Switzerland. Page 75112. DOI 10.1007/978-3-319-09360-4_5. pp 665

Rosenzweig, M.R. and Binswanger, H.P. (1993). Wealth, weather risk and the composition and profitability of agricultural investments. Economic Journal 103(416) : 56-78.

Skees, J., P. Hazell, and M. Miranda (1999), New Approaches to Crop Yield Insurance in Developing Countries. EPTD Discussion Paper No. 55. Washington, DC: International Food Policy Research Institute.

Smith, P., and J. E. Olesen (2010), "Synergies between the mitigation of, and adaptation to, climate change in agriculture", Journal of Agricultural Science Cambridge 148: 543-552.

Subrahmanyam, P and Merwe, P J A Van der and Chiyembekeza, A J and Ngulube, S and Freeman, H A (2000) Groundnut Variety CG 7: A Boost to Malawian Agriculture. International Arachis Newsletter 20. pp. 33-35.

Tchale, H. (2009), "The efficiency of smallholder agriculture in Malawi", African Journal of Agricultural and Resource Economics, 3(2): 101-121.

World Bank (2010). Social dimensions of climate change: equity and vulnerability in a warming world. World Bank, Washington DC

Open Access This chapter is distributed under the terms of the Creative Commons AttributionNonCommercial-ShareAlike 3.0 IGO license (https://creativecommons.org/licenses/by-nc-sa/3.0/ igo/), which permits any noncommercial use, duplication, adaptation, distribution, and reproduction in any medium or format, as long as you give appropriate credit to the Food and Agriculture Organization of the United Nations (FAO), provide a link to the Creative Commons license and indicate if changes were made. If you remix, transform, or build upon this book or a part thereof, you must distribute your contributions under the same license as the original. Any dispute related to the use of the works of the FAO that cannot be settled amicably shall be submitted to arbitration pursuant to the UNCITRAL rules. The use of the FAO's name for any purpose other than for attribution, and the use of the FAO's logo, shall be subject to a separate written license agreement between the FAO and the user and is not authorized as part of this CC-IGO license. Note that the link provided above includes additional terms and conditions of the license.

The images or other third party material in this chapter are included in the chapter's Creative Commons license, unless indicated otherwise in a credit line to the material. If material is not included in the chapter's Creative Commons license and your intended use is not permitted by statutory regulation or exceeds the permitted use, you will need to obtain permission directly from the copyright holder. 